Note: This is the accepted but uncorrected (for final proof) peer reviewed version of the following article: Noor K, Elfeki AMM. Stochastic modelling of a diffusive wave for flood propagation using the random walk particle tracking method in a hypothetical city. Hydrological Processes. 2018;1-15. https://doi.org/10.1002/hyp.13168, which has been published in final form at https://doi.org/10.1002/hyp.13168. This article may be used for non-commercial purposes in accordance with Wiley Terms and Conditions for Use of SelfArchived Versions. 


\title{
Stochastic modelling of a diffusive wave for flood propagation using the random walk particle tracking method in a hypothetical city
}

\author{
Kashif Noor ${ }^{1,2}$ (1) । Amro M.M. Elfeki ${ }^{1}$
}

\author{
${ }^{1}$ Department of Hydrology and Water \\ Resources Management, Faculty of \\ Meteorology, Environment \& Arid Land \\ Agriculture, King Abdulaziz University, Jeddah, \\ Saudi Arabia \\ ${ }^{2}$ Water Resources and Environmental \\ Engineering Research Unit, Faculty of \\ Technology, University of Oulu, Oulu, Finland \\ Correspondence \\ Kashif Noor, Department of Hydrology and \\ Water Resources Management, Faculty of \\ Meteorology, Environment \& Arid Land \\ Agriculture, King Abdulaziz University, Jeddah \\ 21589, Saudi Arabia. \\ Email: kashif.n.afridi@gmail.com; \\ kashif.noor@oulu.fi
}

\section{1 | INTRODUCTION}

Floods are high stages of the river in which the flow overwhelms the natural channel (Chow, 1959). They are natural catastrophic events that have social and economic impacts. In the past, flood devastation has been limited to local and regional scales, but damages from recent flooding events have brought about the interest of researchers to study the flood dynamics on a global scale. Flooding impacts are most severe in densely populated urban areas. This led researchers to develop mathematical methods or techniques for predicting the flood

\section{KEYWORDS}

\begin{abstract}
Deterministic numerical schemes have been widely used for the solution of the diffusive wave (DW) equation, however, these schemes are computationally costly and suffer instability issues. This paper presents a stochastic random walk particle tracking (RWPT) method to solve such an equation for a dam-break flow problem. Three different wave duration scenarios are presented for simulations of the DW for flood flows in a hypothetical city. The hypothetical city is represented by a domain of size $2,000 \mathrm{~m}$ by $500 \mathrm{~m}$ in $\mathrm{x}$ and $\mathrm{y}$ directions, respectively. The domain is divided into $25 \mathrm{~m}$ by $25 \mathrm{~m}$ cells. A dam is located at the upstream of the hypothetical city. Each scenario has a distinct propagation pattern after the dam is breached. Analysed and presented are 18 different simulations, which are composed of three different building configurations, two different bed slopes, and three different shapes of hydrographs. In this method, the flood volume is divided into a large number of particles where each particle carries a fixed amount of the flood volume. These particles undergo convective and diffusive movements, and their superposition represents propagation of the DW in the flow domain. The solution algorithm of the RWPTbased equations is used to compute flood inundation depths in the hypothetical city. Comparison is made among the simulated results from three different shapes of the inflow hydrographs. The proposed stochastic method has two major advantages over traditional deterministic schemes: (a) greater efficiency, thus lesser computational costs, and (b) no instability issues.
\end{abstract}

diffusive wave, floods, random walk, simulations, stochastic modelling

inundations in such urban environments. Formulations of mathematical models are based on the combination of two conservation laws; either the law of conservation of mass and the law of conservation of momentum or the law of conservation of mass and the law of conservation of energy (Lax \& Wendroff, 1960). Based on these laws, wave equations have been derived for representing various wave models. The hydrodynamic wave model derived from the SaintVenant equations is used to represent flood wave propagation. The diffusive wave (DW) model is an approximation of full hydrodynamic wave model and has been widely used in many field applications 
(Ferrick, Bilmes, \& Long, 1984; Moramarco, Pandolfo, \& Singh, 2008 Ponce, 1990; Ponce \& Simons, 1977; Tsai, 2003).

Many modelling approaches are available in the literature to predict the inundation areas that are caused by floods, but these models are based on Eulerian formulation only. Different numerical methods are used to solve high-order non-linear complex mathematical equations describing the flood propagation. Many researchers used Eulerian formulation to obtain solutions of such equations (Fennema \& Chaudhry, 1987; Kazezyılmaz-Alhan \& Medina Jr, 2007; Moussa \& Bocquillon, 2009). Finite difference (Bates, Horritt, \& Fewtrell, 2010; Haltas, Tayfur, \& Elci, 2016; O'brien, Julien, \& Fullerton, 1993), finite volume (Ali, Kimura, \& Shimizu, 2016; Bradford \& Sanders, 2002; Liang et al., 2016), and finite element (Cobby, Mason, Horritt, \& Bates, 2003; Yu \& Lane, 2006; Zhang, Feng, Maksimović, \& Bates, 2016) schemes are well-known numerical schemes, among many others. Solutions of Eulerian equations for flood modelling are not always reliable because they often display numerical instabilities or numerical oscillations and also produce artificial diffusions. Such problems lead to erroneous results of the wave models (Schubert, Sanders, Smith, \& Wright, 2008). Numerical instabilities in such schemes are also caused by the presence of dry areas with moving wet-dry fronts, wherein very high velocities generate negative values of water depths due to the simulation of small local depths of water (Horritt \& Bates, 2002; Prestininzi, 2008). Thus, these schemes involve a high potential of error for modelling of floods.

Stochastic schemes are different alternatives to deterministic schemes for the solution of mathematical models. Considerable progress has occurred in the last three decades in stochastic modelling techniques. The stochastic random walk particle tracking (RWPT) method has been and is being used by many researchers for the solution of the advection-dispersion equation in the field of groundwater hydrology (Banton, Delay, \& Porel, 1997; Emmanuel \& Berkowitz, 2007; Gjetvaj, 1997; Kinzelbach, 1988; Kinzelbach \& Uffink, 1991; Salamon, Fernàndez-Garcia, \& Gómez-Hernández, 2006; Uffink, 1986). Although the literature on this method has been available for a long time, particularly a notable progress in the field has been made by Kinzelbach and Uffink (1991). They suggested the RWPT method for solving the solute transport equation in groundwater domains. In this method, the total mass of solute is represented by a finite number of particles which move in the aquifer in two different types of motion; (a) the advective movement of particles due to the flow velocity and (b) the dispersive movement of particles due to the dispersion process. The same concept was used by Elfeki, Ewea, and Al-Amri (2011) for surface water transport but with some limitations.

This research paper presents an alternative approach for modelling of the DWs. The proposed approach utilizes the stochastic RWPT technique for solving a two dimensional (2-D) DW equation instead of using the traditional Eulerian scheme. An algorithm based on the RWPT technique is developed to simulate three different shapes of the inflow flood hydrographs, flowing from a reservoir after the breach of a dam towards the hypothetical city. Simulation results are compared based on the shapes of the inflow flood hydrographs in order to show the varying propagation impacts of a DW in the hypothetical city. The three different shapes of the flood hydrographs represent three different duration flood waves. This study shows comparison of flood inundation depths resulting from three different shapes of inflow hydrographs for selecting the best scenario when handling situations of a real flood event. Simulated results corroborate the potential of the newly developed RWPT-based algorithm for modelling flood events in cities.

\section{2 | METHODOLOGY}

The hydrodynamic wave model in 2-D is described by the continuity and momentum equations, represented by Equations (1), (2), and (3) for unsteady flow (Chow, 1959).

$$
\begin{gathered}
\frac{\partial h}{\partial t}+\frac{\partial h u}{\partial x}+\frac{\partial h v}{\partial y}=0, \\
\frac{\partial h u}{\partial t}+\frac{\partial\left(h u^{2}\right)}{\partial x}+\frac{\partial(u v)}{\partial y}+g h \frac{\partial h}{\partial x}+g\left(h \frac{\partial z}{\partial x}-S_{f x}\right)=0, \\
\frac{\partial h v}{\partial t}+\frac{\partial(h u v)}{\partial x}+\frac{\partial\left(h v^{2}\right)}{\partial y}+g h \frac{\partial h}{\partial y}+g\left(h \frac{\partial z}{\partial y}-S_{f y}\right)=0,
\end{gathered}
$$

where $u, v=$ velocity of flow in $x$ and $y$ directions, respectively, $h=$ depth of water, $g=$ gravitational acceleration, $z$ = bed elevation, $S_{f x}$, $\mathrm{S}_{\mathrm{fy}}=$ friction slope in $x$ and $y$ directions, respectively (which can be evaluated by Manning's equation), and $x, y=$ spatial coordinate in $x$ and $y$ direction, respectively.

The hydrodynamic wave model involves uncertainties of parameters due to its high non-linearity. In order to find alternatives for this complex nature of the hydrodynamic wave model, researchers used approximate versions of the full hydrodynamic wave model for their investigations (Leandro, Chen, \& Schumann, 2014; Liu, Gebremeskel, De Smedt, Hoffmann, \& Pfister, 2003; Moussa, 1996; Moussa \& Bocquillon, 2009; Noor \& Elfeki, 2017). The DW model is an approximation of the full hydrodynamic wave model in which the inertial and local acceleration terms are ignored in the momentum equations. It produces better results than its simplified version, kinematic wave model. The momentum equations in $x$ and $y$ directions for the DW model are given as follows:

$$
\begin{aligned}
& \frac{\partial h}{\partial x}+\frac{\partial z}{\partial x}+S_{f x}=0 \\
& \frac{\partial h}{\partial y}+\frac{\partial z}{\partial y}+S_{f y}=0 .
\end{aligned}
$$

By rearranging momentum equations of the DW model, the frictional slopes $\left(\mathrm{S}_{f x}\right.$ and $\left.\mathrm{S}_{f y}\right)$ in $x$ and $y$ directions can be obtained, as expressed in Equations (6) and (7), which are dependent on the water surface gradients $\left(\frac{\partial h}{\partial x}\right.$ and $\left.\frac{\partial h}{\partial y}\right)$ and ground surface gradients $\left(\frac{\partial z}{\partial x}\right.$ and $\left.\frac{\partial z}{\partial y}\right)$ in $x$ and $y$ directions, respectively.

$$
\begin{aligned}
& S_{f x}=-\frac{\partial h}{\partial x}-\frac{\partial z}{\partial x}, \\
& S_{f y}=-\frac{\partial h}{\partial y}-\frac{\partial z}{\partial y} .
\end{aligned}
$$


For obtaining the 2-D DW equation, first the continuity equation (Equation (1)) is expanded to the form, represented by Equation (8) and then using momentum equations (Equations (6) and (7)) for representing the frictional slopes in terms of velocities, where velocities are function of water elevation, $h$, and the water surface gradient $\frac{\partial h}{\partial x}$ and $\frac{\partial h}{\partial y}$, as expressed in Equations (9) and (10).

$$
\begin{aligned}
\frac{\partial h}{\partial t}+u \frac{\partial h}{\partial x}+h \frac{\partial u}{\partial x}+v \frac{\partial h}{\partial y}+h \frac{\partial u}{\partial y}=0, \\
u=u\left(h, \frac{\partial h}{\partial x}\right), \\
v=v\left(h, \frac{\partial h}{\partial y}\right) .
\end{aligned}
$$

The continuity equation and the momentum equations of the 2-D DW model are solved using the principle of differentiation on the continuity equation to produce the following 2-D DW equation (Equation (11)):

$$
\frac{\partial h}{\partial t}+u \frac{\partial h}{\partial x}+\frac{\partial(h u) \partial^{2} h}{\partial\left(\frac{\partial h}{\partial x}\right) \partial x^{2}}+v \frac{\partial h}{\partial y}+\frac{\partial(h v) \partial^{2} h}{\partial\left(\frac{\partial h}{\partial y}\right) \partial y^{2}}=0
$$

Equation (11) can be expressed in the form of 2-D advectiondiffusion equation, which is represented by Equation (12):

$$
\frac{\partial h}{\partial t}+u \frac{\partial h}{\partial x}+v \frac{\partial h}{\partial y}-D_{x x} \frac{\partial^{2} h}{\partial x^{2}}-D_{y y} \frac{\partial^{2} h}{\partial y^{2}}=0,
$$

where $D_{x x}$ and $D_{y y}$ are diffusion coefficients in $x$ and $y$ directions, respectively

$$
D_{x x}=-\frac{\partial(h u)}{\partial\left(\frac{\partial h}{\partial x}\right)}, \text { and } \quad D_{y y}=-\frac{\partial(h v)}{\partial\left(\frac{\partial h}{\partial y}\right)} \text {. }
$$

The diffusion coefficients are estimated by using Manning's equation for velocities in both directions and assuming the overland flood flow as the flow in a wide rectangular channel, where the hydraulic radius, $R$, equals the water depth, $h$. For instance, the diffusion coefficient in the $x$ direction is given by Equation (13):

$$
D_{x x}=-\frac{\partial(h u)}{\partial\left(\frac{\partial h}{\partial x}\right)}=\frac{\partial\left(\frac{1}{h} h^{\frac{5}{3}} \sqrt{\frac{\partial z}{\partial x}+\frac{\partial h}{\partial x}}\right)}{\partial\left(\frac{\partial h}{\partial x}\right)}=\frac{\frac{1}{n} h^{\frac{5}{3}}}{2\left(\sqrt{\frac{\partial z}{\partial x}+\frac{\partial h}{\partial x}}\right)}
$$

After some manipulation, the final expression for the diffusion coefficient in $x$ direction, that is, $D_{x x}$, is given by Equation (14). The expression for the diffusion coefficient in $y$ direction, that is, $D_{y y}$, can be obtained in the similar fashion, as represented by Equation (15):

$$
D_{x x}=\frac{h u}{2\left(\frac{\partial z}{\partial x}+\frac{\partial h}{\partial x}\right)},
$$

$$
D_{y y}=\frac{h v}{2\left(\frac{\partial z}{\partial y}+\frac{\partial h}{\partial y}\right)}
$$

Because the diffusion terms depend on the flow depth, and the water surface gradients and the ground surface gradients are space dependent, it is better to express Equation (12) in the form of Equation (16), as given by:

$$
\frac{\partial h}{\partial t}+u \frac{\partial h}{\partial x}+v \frac{\partial h}{\partial y}-\frac{\partial}{\partial x}\left[D_{x x} \frac{\partial h}{\partial x}\right]-\frac{\partial}{\partial y}\left[D_{y y} \frac{\partial h}{\partial y}\right]=0 .
$$

Equation (16) is analogous to the form of a 2-D advectiondiffusion equation for the solute transport in porous media, as represented by Equation (17), where the direction of flow is aligned with the principal components of the diffusion tensor (Bear, 2013):

$$
\frac{\partial C}{\partial t}+u \frac{\partial C}{\partial x}+v \frac{\partial C}{\partial y}-\frac{\partial}{\partial x}\left[D_{x x} \frac{\partial C}{\partial x}\right]-\frac{\partial}{\partial y}\left[D_{y y} \frac{\partial C}{\partial y}\right]=0
$$

where $C$ = solute concentration.

Many researchers solved advection-diffusion equation by the random walk theory (Abulaban, Nieber, \& Misra, 1998; Kinzelbach, 1988; Kinzelbach \& Uffink, 1991). A similar approach is used in this study for solving the 2-D DW equation (i.e., Equation (16)).

\subsection{Analogy of the diffusion equation with the random walk theory}

The RWPT method does not directly solve the transport equation for a DW. The method instead provides the solution for the FokkerPlanck equation. This is because the Fokker-Planck equation is not analogous to the transport equation in general. Typically, the Fokker-Planck equation is a conservation equation describing the particle density distribution function $(f)$ for movement of particles in a random field. The generalized forms of the Fokker-Planck equation (Equation (18)) are given by Tompson (1993) and Abulaban et al. (1998):

$$
\frac{\partial f}{\partial t}+\nabla \cdot(A f)-\nabla^{2}:\left[\frac{B \cdot B^{T}}{2} f\right]=0
$$

where $\boldsymbol{A}=$ drift vector, $\boldsymbol{B}=$ displacement matrix, representing the dispersion tensor, $f=$ particle density function, and colon (:) is used for representing the outer product for multiplying two tensors.

The expanded form of the Fokker-Planck equation with the diffusion terms is given by Equation (19):

$$
\frac{\partial f}{\partial t}+u^{\prime} \frac{\partial f}{\partial x}+v^{\prime} \frac{\partial f}{\partial y}-\frac{\partial^{2}}{\partial x^{2}}\left(D_{x x} f\right)-\frac{\partial^{2}}{\partial y^{2}}\left(D_{y y} f\right)=0
$$

where $u^{\prime}$ and $v^{\prime}$ are the drift velocities in $x$ and $y$ directions, respectively.

After expanding Equation (16) and rearranging the terms, the 2-D DW equation becomes

$$
\frac{\partial h}{\partial t}+\left(u-\frac{\partial D_{x x}}{\partial x}\right) \frac{\partial h}{\partial x}+\left(v-\frac{\partial D_{y y}}{\partial x}\right) \frac{\partial h}{\partial y}-D_{x x} \frac{\partial^{2} h}{\partial x^{2}}-D_{y y} \frac{\partial^{2} h}{\partial y^{2}}=0 .
$$


The analogy between Equations (19) and (20) shows that

$$
\begin{aligned}
& u^{\prime}=u-\frac{\partial D_{x x}}{\partial x} \\
& v^{\prime}=v-\frac{\partial D_{y y}}{\partial x} .
\end{aligned}
$$

The corresponding solution in the form of the RWPT equation is given by Equation (21):

$$
X_{p}(t+\Delta t)=X_{p}(t)+A\left(X_{p}, t\right)+B\left(X_{p}, t\right) \cdot \xi(t) \sqrt{\Delta t},
$$

where $X_{p}(t)=$ position vector $\left(X_{p}(t) Y_{p}(t)\right)^{T}$ of a particle at time $t$, $X_{p}(t+\Delta t)=$ position vector $\left(X_{p}(t+\Delta t) Y_{p}(t+\Delta t)\right)^{T}$ of a particle at time $t+\Delta t, \Delta t=$ time step, and $\xi(t)=$ vector of distributed random variables with a zero mean and a unit variance.

The RWPT equation solves the Fokker-Planck equation. If a large number of particles are moving sporadically in a flow field starting from $X_{0}$ and $Y_{0}$ at $t_{0}$, and the probability density of the particles $f$ at any time, $t$ is calculated by finding the fraction of particles in the vicinity of a small area around the points $X$ and $Y$ in the flow field. The form of the extended solution of the Fokker-Planck by RWPT equations are represented by Equations (22) and (23), respectively (Kinzelbach, 1986; Uffink, 1990):

$$
\begin{aligned}
X_{p}(t+\Delta t)= & X_{p}(t)+u \Delta t+\left(\frac{\partial D_{x x}}{\partial x}\right) \Delta t \\
& +\frac{u}{|V|} Z \sqrt{2 a_{L}|V| \Delta t}-\frac{v}{|V|} Z^{\prime} \sqrt{2 a_{T}|V| \Delta t} \\
Y_{p}(t+\Delta t)= & Y_{p}(t)+v \Delta t+\left(\frac{\partial D_{y y}}{\partial y}\right) \Delta t \\
& +\frac{u}{|V|} Z \sqrt{2 a_{L}|V| \Delta t}-\frac{v}{|V|} Z^{\prime} \sqrt{2 a_{T}|V| \Delta t}
\end{aligned}
$$

where $X_{p}=$ particle position in $x$ direction, $Y_{p}=$ particle position in $y$ direction, $Z$ and $Z^{\prime}=$ random numbers with zero mean and unit variance, $|\mathrm{V}|=$ resultant velocity $\left(|\mathrm{V}|=\sqrt{\mathbf{u}^{2}+\mathbf{v}^{2}}\right), \alpha_{\mathrm{L}}=$ longitudinal diffusivity, $\alpha_{T}=$ transverse diffusivity, $D_{i j}=\left[\alpha_{L}|V|\right] \delta_{i j}+\left[\alpha_{L}-\alpha_{T}\right] \frac{u v}{|V|}$ (diffusion tensor), $\delta_{i j}=$ delta function (if $i=j, \delta=1$ and if $i \neq j, \delta=0$ ), and $u, v$ are overland flow velocities in $x$ and $y$ directions, respectively.

The derivatives of the diffusion coefficients in Equations (22) and (23) are evaluated using the finite difference scheme between two adjacent cells. These terms in the RWPT equations play a significant role to overcome the unrealistic accumulation of particles in stagnation zones.

Typically, Manning's formula is used for the velocity computations in $x$ and $y$ directions, which are given by Equations (24) and (25):

$$
\begin{aligned}
& u=\frac{1}{n} R_{h}{ }^{2 / 3} S_{x}{ }^{1 / 2}, \\
& v=\frac{1}{n} R_{h}{ }^{2 / 3} S_{y}{ }^{1 / 2},
\end{aligned}
$$

where $R_{h}=$ hydraulic radius, and $S_{x}=\partial z / \partial x$ and $S_{y}=\partial z / \partial y$ are ground surface slopes of cells in $x$ and $y$ directions, respectively.

McCuen (1989) simplified Manning's formula for velocity computations by assuming the values for $R_{h}$ and $n$. This forms a relationship between the velocity and bed slope. His empirical equations for overland flow velocities are shown in Equations (26) and (27):

$$
u=\frac{k}{3.281}\left(\frac{\Delta z}{\Delta x} 100\right)^{0.5}
$$

$$
v=\frac{k}{3.281}\left(\frac{\Delta z}{\Delta y} 100\right)^{0.5}
$$

where $k=\frac{1}{n} R_{h}{ }^{2 / 3}$ roughness coefficient which is tabulated in McCuen (1989; the tabulated values for $k$ are in FPS system, therefore, these values are converted to $\mathrm{SI}$ system in the above equations), $\Delta x$ and $\Delta y=$ cell dimensions in $x$ and $y$ directions, respectively, and $\Delta z=\left(z_{2}-z_{1}\right)$ is the difference in the bed elevations between two adjacent cells.

Three different duration scenarios are used for the computation of inundation depths. The inundation depths for a pulse with a very short duration (considered as an instantaneous duration case in this study) and for a pulse with an infinite duration in a given cell are computed by using Equations (28) and (29), respectively:

$$
h(t)=\frac{n(t) V_{p}}{\Delta x \Delta y}
$$

$$
h(t)=h(t-\Delta t)+\frac{n(t) V_{p}}{\Delta x \Delta y}
$$

where $V_{p}=$ volume of water per particle, $h(t)=$ inundation depth at time $t, h(t-\Delta t)=$ inundation depth at time, $t-\Delta t$ and $n(t)=$ number of particles at time, $t$. Equation (29) represents a convolution over the time step, $\Delta t$.

In order to compute the inundation depths for a pulse with a finite duration (the finite duration corresponds to the time base of a flood hydrograph), Equations (29) and (30) are used:

$$
h(t)=h(t-\Delta t)+\frac{n(t) V_{p}}{\Delta x \Delta y}-h(t-\tau) .
$$

When there is an inflow of a flood from the location of a dam (i.e., $t \leq \tau$ ), the inundation depth is calculated using the convolution formula (represented by Equation (29)). When the inflow of flood is stopped (i.e., $t>\tau$ ), the deconvolution formula (represented by Equation (30)) is used for the computation of remaining inundation depths.

\section{2 | Data used for the hypothetical city}

In this study, a hypothetical city is represented by a domain of $2,000 \mathrm{~m}$ in $x$ direction and $500 \mathrm{~m}$ in $\mathrm{y}$ direction (Figure 1). Three differ- F1 ent types of building configurations are considered: (a) single block of buildings, (b) detached buildings, and (c) random buildings (Figure 2). F2 The domain of each building configuration is divided into a number of cells, wherein each cell has the dimensions of $25 \mathrm{~m}$ by $25 \mathrm{~m}$.

A dam is located at $x=300 \mathrm{~m}$ in the city with a width of $500 \mathrm{~m}$. In the example presented herein, it is assumed that the middle third of the dam breaks, and the city is flooded. The flood is monitored at different times to study the propagation of the flood wave and its analysed impacts in the city. The area of a reservoir is $300 \mathrm{~m}$ by $500 \mathrm{~m}$ (see Figure 2). The number of particles is 100,000 that represent 
Domain

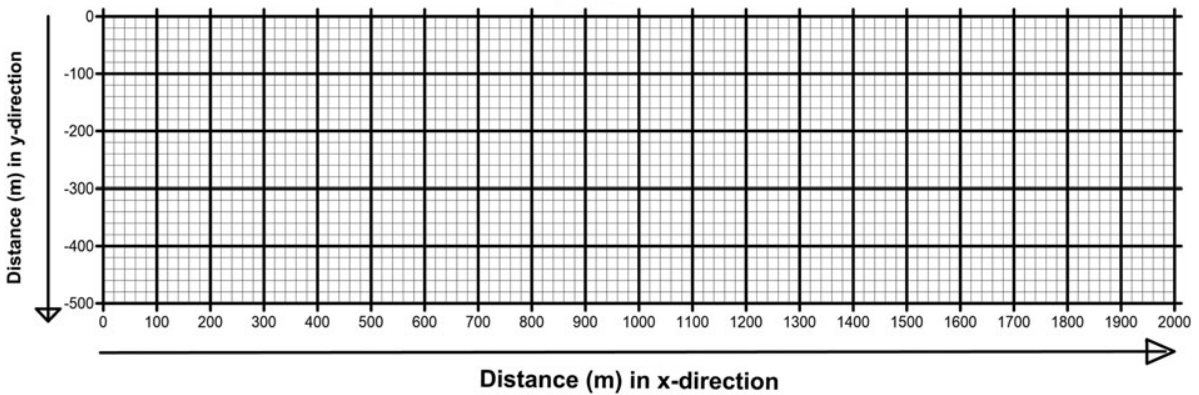

(a) Single block of buildings

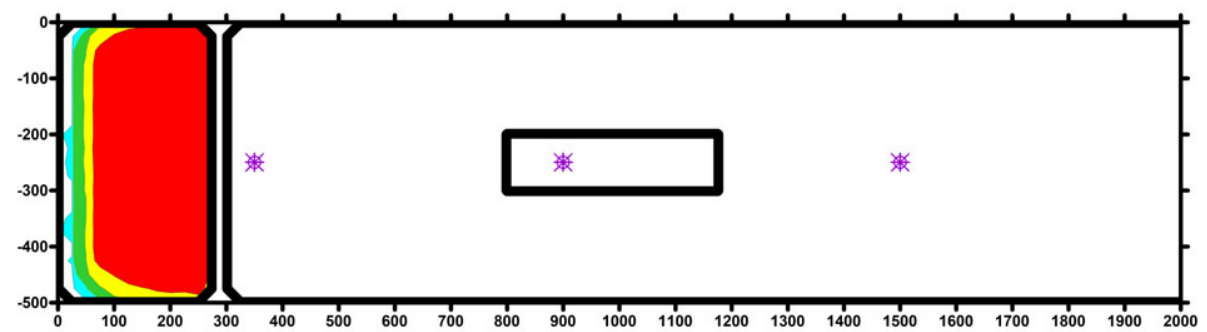

(b) Detached buildings

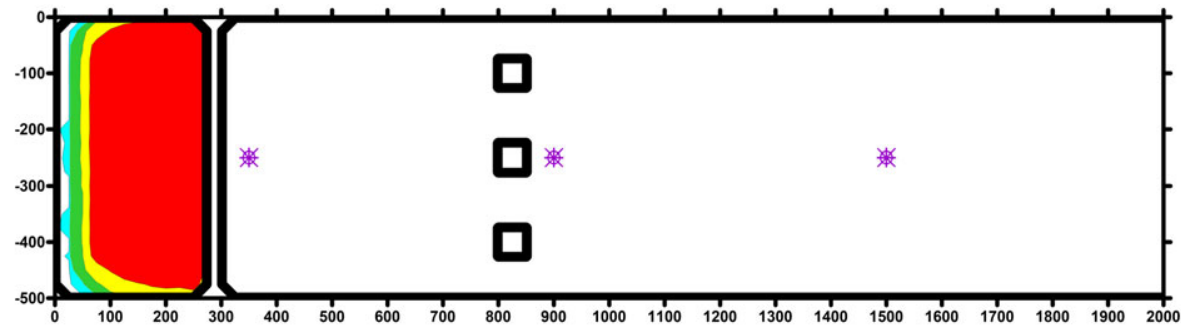

(c) Random buildings

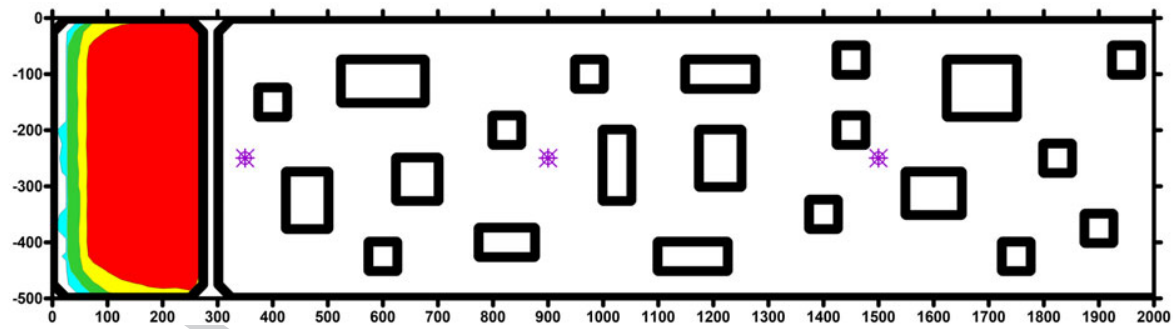

FIGURE 2 Three different types of building configurations are shown: (a) single block of buildings, (b) detached buildings, and (c) random buildings with three chosen locations used for computing the depth hydrographs

the volume of the hydrograph. The longitudinal diffusivity $\left(\alpha_{L}\right)$ and the transverse diffusivity $\left(\alpha_{T}\right)$ are $5 \mathrm{~m}$. The time step $(\Delta t)$ is $1 \mathrm{~min}$. Three different duration scenarios are used to represent the flood hydrographs F3 (Figure 3). For an instantaneous pulse, the duration, $\tau$, is $1 \mathrm{~min}$, for an infinite pulse, $\tau$ is infinite, that is, $\propto$ min, and for a finite pulse, $\tau$ is $20 \mathrm{~min}$. The time span for the simulations is $840 \mathrm{~min}$. The parameters T1 are summarized in Table 1.

F4 Two types of artificial digital elevation models (DEMs; Figure 4) are considered in this study in which the flood flow is driven from the left to the right direction, and the flow is prohibited from the top and bottom boundaries. The first DEM is generated with a uniform global slope $\left(S_{1}\right)$, and the second DEM is generated with randomly variable local slopes but represented with an average global slope $\left(S_{2}\right)$. The buildings act as barriers to the particle movement, wherein the particles attain equal probabilities of 0.5 for moving in both directions (right and left of the building) while facing buildings.

\section{3 | RESULTS}

In this section, three cases are discussed; Case 1: a pulse of the flood with an instantaneous duration, Case 2: a pulse of the flood with an infinite duration, and Case 3: a pulse of the flood with a finite duration. In this paper, 18 different simulations based on the RWPT 


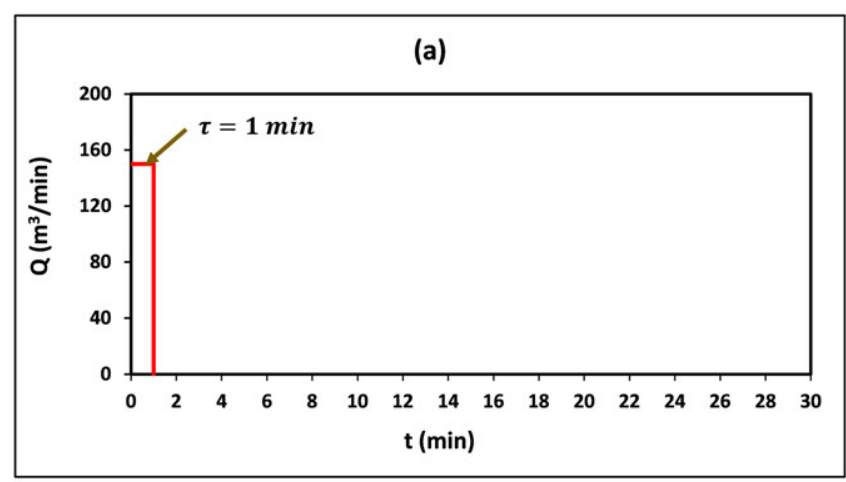

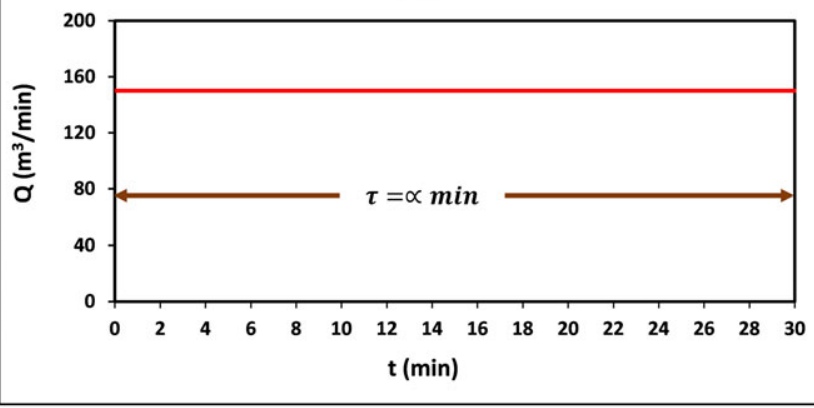

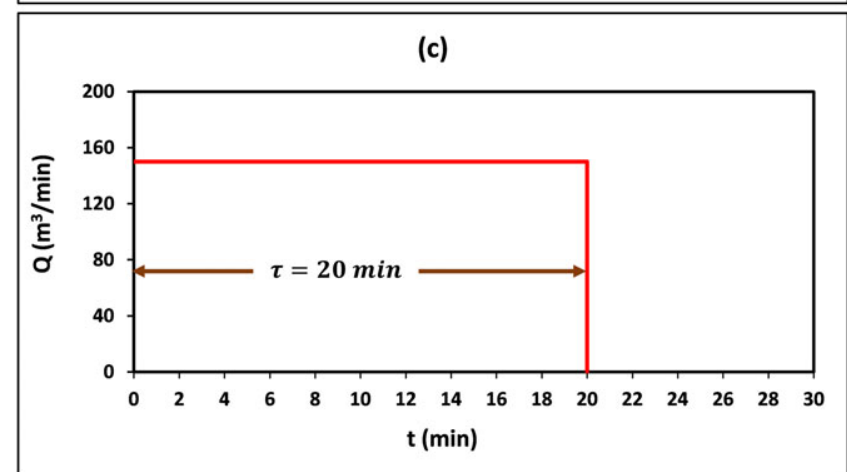

FIGURE 3 Flood hydrographs representing three types of pulses: (a) instantaneous pulse with a duration, $\tau=1 \mathrm{~min}$, (b) infinite pulse with a duration, $\tau=\propto \min$, and (c) finite pulse with a duration, $\tau=20 \mathrm{~min}$ method are analysed for three different building configurations, two different slopes, and three different shapes of hydrographs. All figures in each case (Figures 5-10) represent three simulations performed in three different types of building configurations. Two earth surface profiles are used (one is the DEM with a uniform global slope, whereas the other is the DEM with randomly variable local slopes), representing six simulations for each case discussed herein. Initially, the dam reservoir is full of water, and suddenly, the dam breaks (the middle one third of the dam length is removed). The flow is released immediately in the form of a flood. Three different shapes of inflow hydrographs (in the form of pulses), as shown in Figure 3, represent the propagation of a DW in the hypothetical city, where pulses are discussed for three different cases. Simulated results show the different propagating effects of DWs in the example city. The flood propagations are presented temporally at 10,100, 220, and $420 \mathrm{~min}$. The same colour scale is used for all the three cases in order to make comparison among the cases easier.

\section{1 | Case 1: A pulse of flood with an instantaneous duration}

A pulse with a very short duration (considered as an instantaneous duration, see Figure 3a) is a flood wave from the reservoir that lasts for a very short time ( $\tau=1 \mathrm{~min}$ ), occurring after the breach of a dam (see Figure 2). The DW that has the duration of $1 \mathrm{~min}$ is considered as an instantaneous DW. The occurrence of an instantaneous duration pulse is not practically possible. However, the discussion of such a short duration wave is presented as a reference case for the comparisons.

Figure 5 represents simulations performed for the DEM with a uniform global slope, whereas Figure 6 represents simulations performed for the DEM with randomly variable local slopes. In Case 1 , because the pulse is of an instantaneous duration (i.e., $\tau=1 \mathrm{~min}$ ), corresponding depths are very small for both types of DEM. The maximum depth of $0.1 \mathrm{~m}$ (represented by the red colour) does not occur in both of the figures (Figures 5 and 6) representing the downstream

TABLE 1 Summary of the parameters and data used for the hypothetical city

\begin{tabular}{|c|c|c|c|c|}
\hline S. no & Parameters & Instantaneous pulse & Infinite pulse & Finite pulse \\
\hline 1 & Discharge, $\mathrm{Q}\left(\mathrm{m}^{3} / \mathrm{min}\right)$ & 150 & 150 & 150 \\
\hline 2 & Duration of a pulse, $\tau$ (min) & 1 & $\propto$ & 20 \\
\hline 3 & Roughness coefficient, $\mathrm{k}$ & 1 & 1 & 1 \\
\hline 4 & Number of particles, $\mathrm{N}$ & 100,000 & 100,000 & 100,000 \\
\hline 5 & Area of a reservoir, $A\left(\mathrm{~m}^{2}\right)$ & $300 \times 500$ & $300 \times 500$ & $300 \times 500$ \\
\hline 6 & Cell dimensions $\left(\mathrm{m}^{2}\right)$ & $25 \times 25$ & $25 \times 25$ & $25 \times 25$ \\
\hline 7 & Overall slope of a DEM (uniform global slope, Figure 4a) & 0.0005 & 0.0005 & 0.0005 \\
\hline 8 & Overall slope of a DEM (randomly variable local slopes, Figure 4b) & 0.0005 & 0.0005 & 0.0005 \\
\hline 9 & Time step, $t$ (min) & 1 & 1 & 1 \\
\hline 10 & Longitudinal diffusivity, $\alpha_{L}(\mathrm{~m})$ & 5 & 5 & 5 \\
\hline 11 & Transverse diffusivity, $\alpha_{T}(\mathrm{~m})$ & 5 & 5 & 5 \\
\hline 12 & Average velocity (DEM with a uniform global slope), $V_{\text {avg }}(\mathrm{m} / \mathrm{min})$ in $x$ direction & 4.09 & 4.09 & 4.09 \\
\hline 13 & Average velocity (DEM with randomly variable local slopes), $V_{\text {avg }}(\mathrm{m} / \mathrm{min})$ in $x$ direction & 4.09 & 4.09 & 4.09 \\
\hline
\end{tabular}

Note. DEM: digital elevation model. 

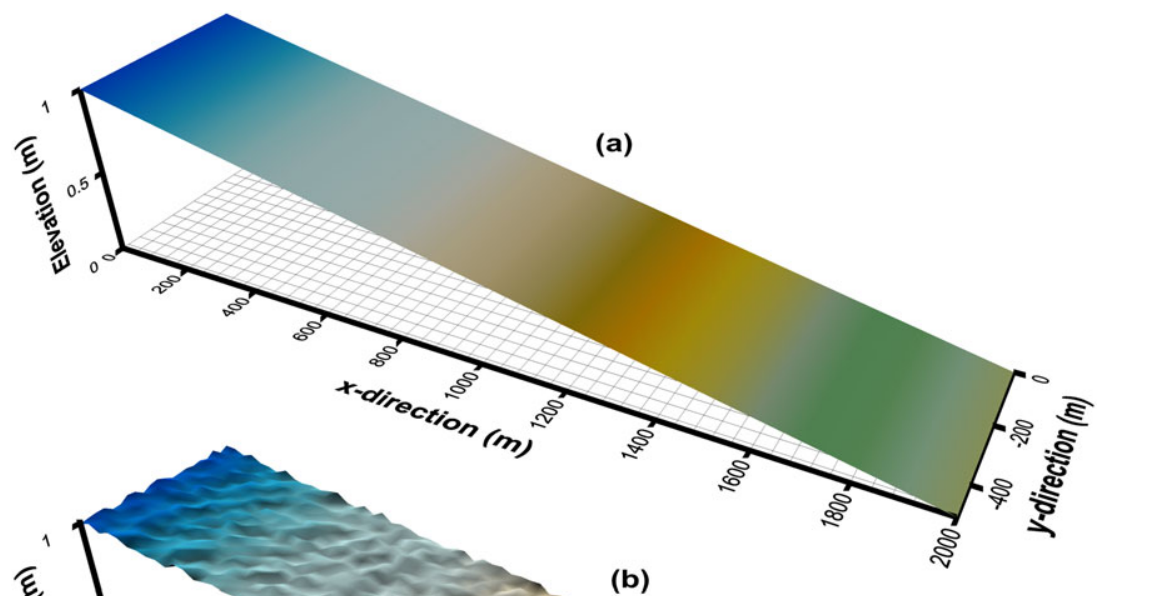

FIGURE 4 Digital elevation models are represented by two different types of gradients: (a) uniform slope and (b) randomly variable local slopes but with a uniform global slope

(a)
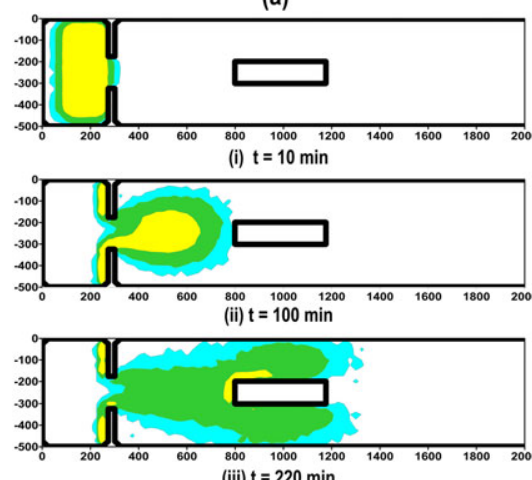

(iii) $\mathrm{t}=220 \mathrm{~min}$

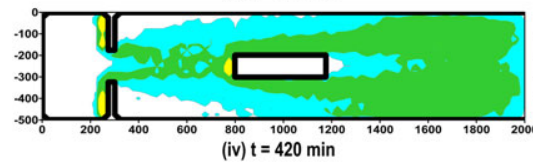

(b)
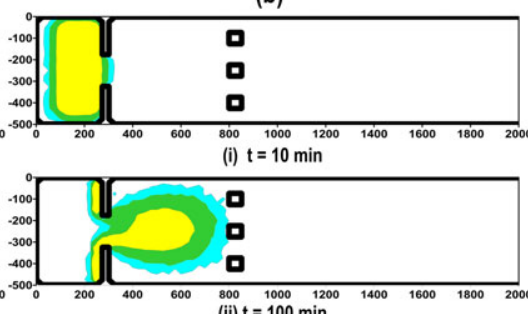

(ii) $\mathrm{t}=100 \mathrm{~min}$
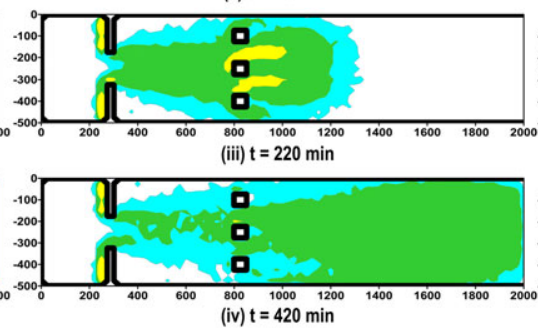

Depth (m)

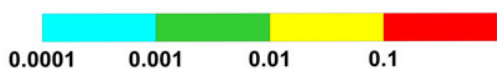

(b)

FIGURE 5 Simulation of a pulse with an instantaneous duration of the diffusive wave for time periods of (i) $t=10 \mathrm{~min}$, (ii) $t=100$ min, (iii) $t=220 \mathrm{~min}$, and (iv) $t=420 \mathrm{~min}$ in a hypothetical city, consisting of (a) single block of buildings, (b) detached buildings, and (c) random buildings (digital elevation model: uniform global slope)

hypothetical city, apart from Figure 6 where it occurs in the reservoir at all temporal simulations. Because of the random changes in the local slopes, some of the slopes are negative. Hence, the flood starts filling the ditches or pits initially until it overwhelms these ditches or ponds, thereby causing an increase in inundation depths.
In Figure 5, the DW surrounds the buildings at $t=220 \mathrm{~min}$ for the first two types of building configurations (single block of buildings and detached buildings) and at $t=100$ min for the other type of building configurations (random buildings), where particles have a probability of 0.5 for drifts in opposite directions parallel to the fronts of buildings 
(a)
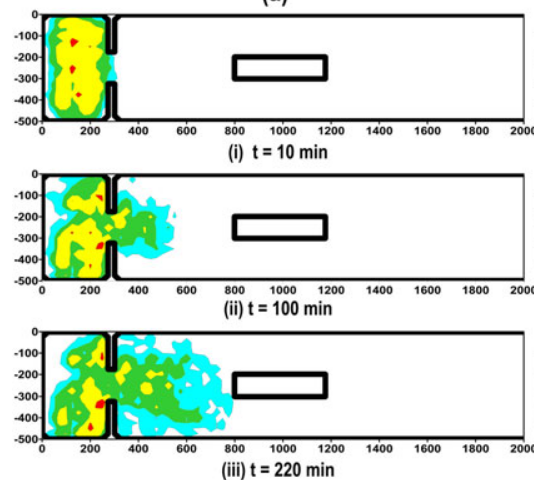

(iii) $\mathrm{t}=220 \mathrm{~min}$

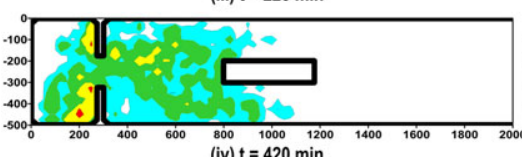

(iv) $\mathrm{t}=420 \mathrm{~min}$ (b)

(i) $t=10 \mathrm{~min}$
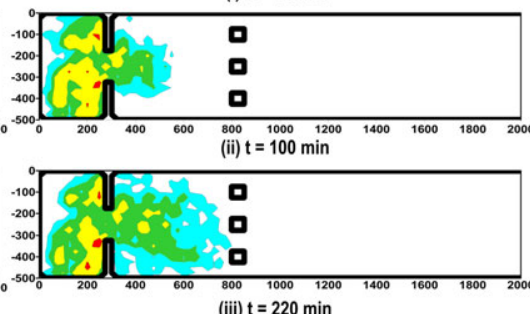

(iii) $\mathrm{t}=\mathbf{2 2 0} \mathrm{min}$

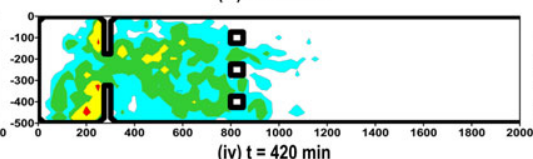

(iv) $\mathrm{t}=420 \mathrm{~min}$

Depth $(m)$

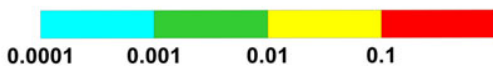

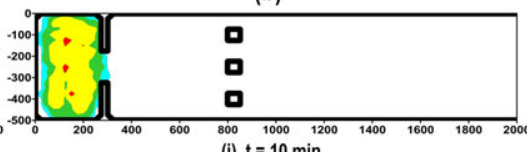

(c)

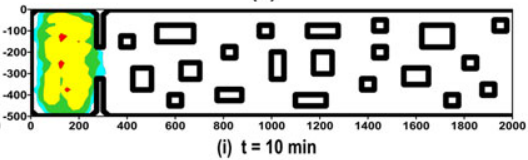

(i) $\mathrm{t}=10 \mathrm{~min}$
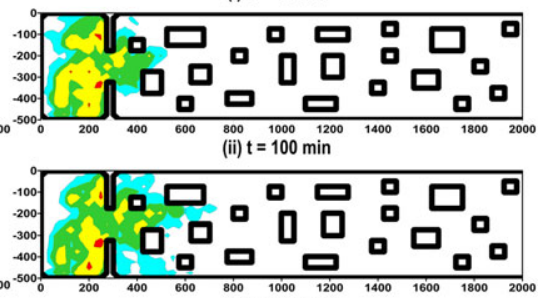

(iii) $\mathrm{t}=220 \mathrm{~min}$

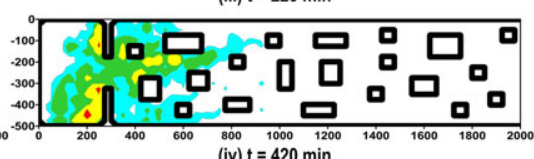

(iv) $\mathrm{t}=420 \mathrm{~min}$

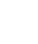

(a)
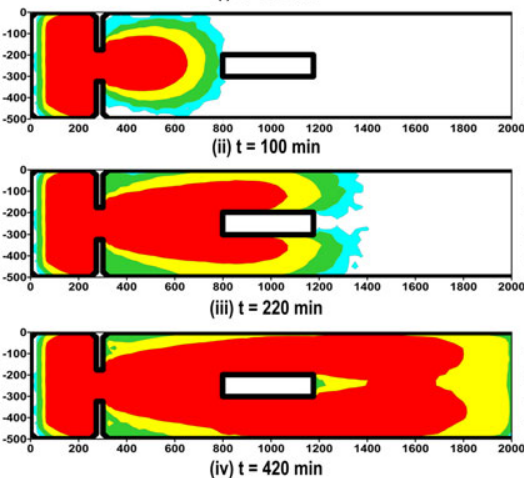

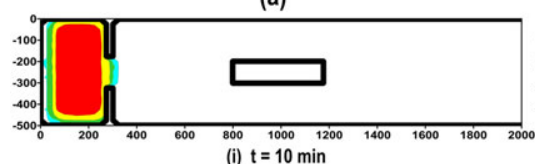

(b)
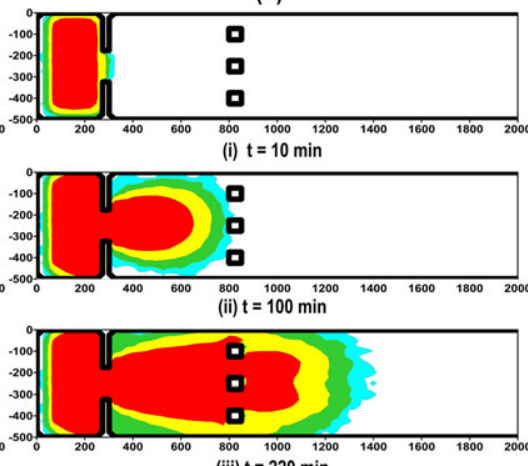

(iii) $\mathrm{t}=220 \mathrm{~min}$

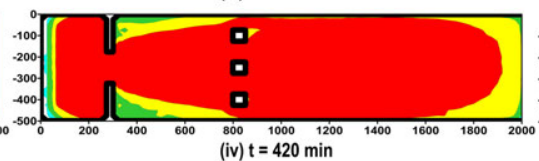

Depth (m)

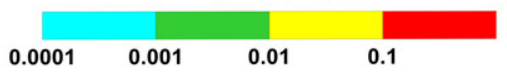

(c)
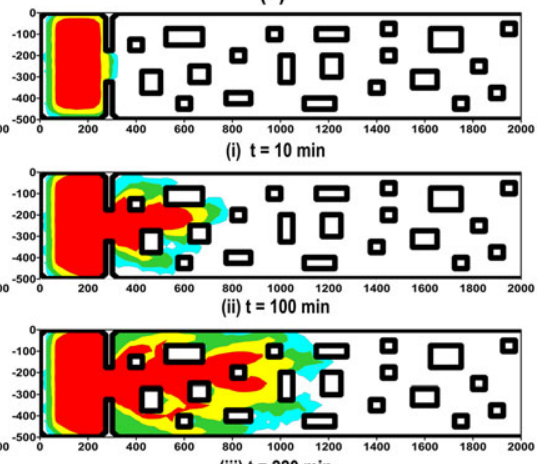

(iii) $\mathrm{t}=220 \mathrm{~min}$

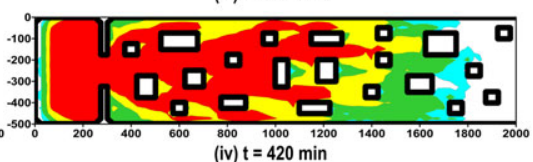

(iv) $\mathrm{t}=420 \mathrm{~min}$

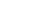

FIGURE 7 Simulation of a pulse with an infinite duration of the diffusive wave for time periods of (i) $t=10 \mathrm{~min}$, (ii) $t=100 \mathrm{~min}$, (iii) $t=220 \mathrm{~min}$, and (iv) $t=420 \mathrm{~min}$ in a hypothetical city, consisting of (a) single block of buildings, (b) detached buildings, and (c) random buildings (digital elevation model: uniform global slope) in order to move around them in the open spaces of streets or roads. The algorithm works as intended, and the flood flow does not go inside buildings but rather moves around them. The yellow colour represents depths in the range of 0.01 to $0.1 \mathrm{~m}$, which occur initially after the flood starts flowing in the hypothetical city. After some time, it starts to disappear (e.g., at $t=420 \mathrm{~min}$, except in front of buildings). The range of the blue colour depths is 0.0001 to 0.001 $\mathrm{m}$, and the green colour depths is 0.001 to $0.01 \mathrm{~m}$. These small depths show that the instantaneous duration flood causes small inundations in the flow domain. Simulations of the DW are shown till $420 \mathrm{~min}$ of elapsed time.

In Figure 6, the pattern of DW propagation is different from the pattern discussed in the last paragraph. For instance, the DW does not surround the buildings at $t=220 \mathrm{~min}$ in the domains of single block of buildings and detached buildings but surrounds them at $t=420$ min. Results for the domain of random buildings are similar to the previous case where the flood surrounds the buildings at $t=100 \mathrm{~min}$. 
(a)
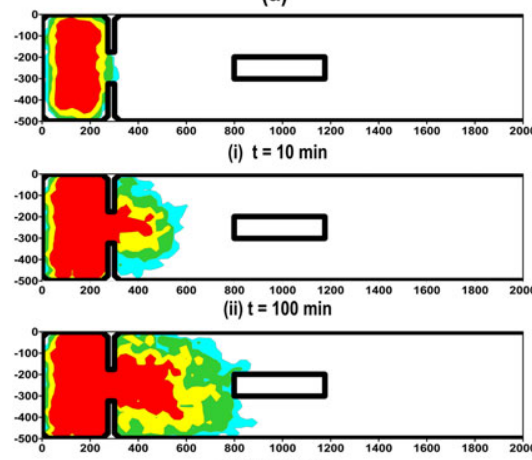

(iii) $\mathrm{t}=220 \mathrm{~min}$

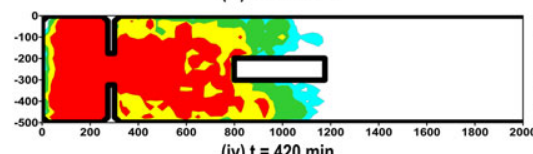

(iv) $\mathrm{t}=\mathbf{4 2 0} \mathrm{min}$ (b)

(i) $\mathrm{t}=10 \mathrm{~min}$
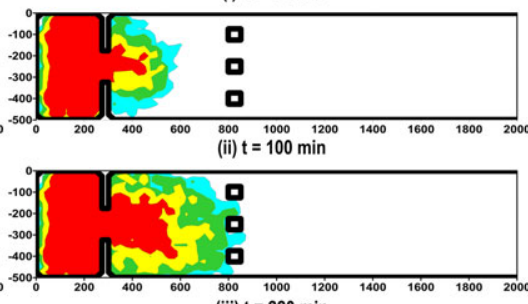

(iii) $\mathrm{t}=220 \mathrm{~min}$

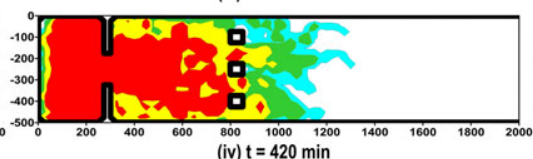

(iv) $\mathrm{t}=420 \mathrm{~min}$

Depth (m)

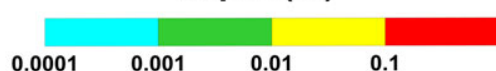

0.0001

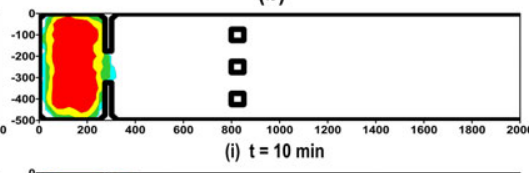

(c)

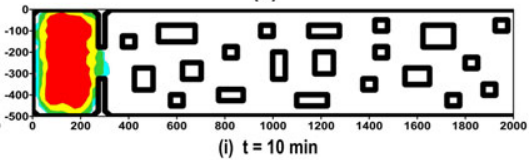

(i) $\mathrm{t}=10 \mathrm{~min}$
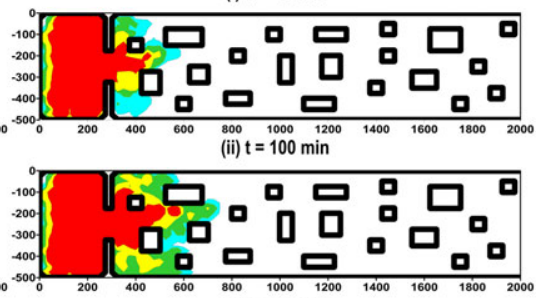

(iii) $\mathrm{t}=\mathbf{2 2 0} \mathrm{min}$

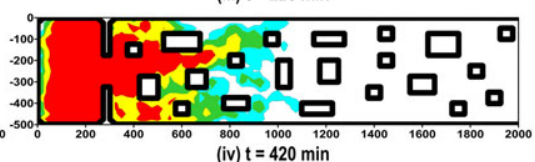

(iv) $\mathrm{t}=420 \mathrm{~min}$

(1) (a)
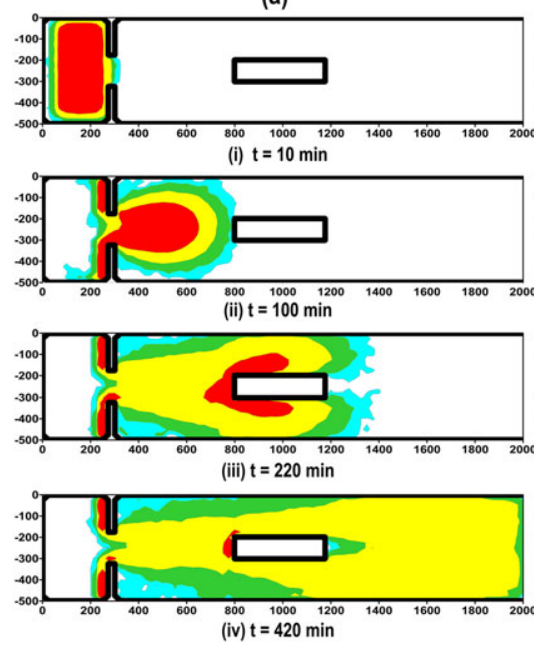

FIGURE 8 Simulation of a pulse with an infinite duration of the diffusive wave for time periods of (i) $t=10 \mathrm{~min}$, (ii) $t=100 \mathrm{~min}$, (iii) $t=220 \mathrm{~min}$, and (iv) $t=420 \mathrm{~min}$ in a hypothetical city, consisting of (a) single block of buildings, (b) detached buildings, and (c) random buildings (digital elevation model: randomly variable local slopes) (b)
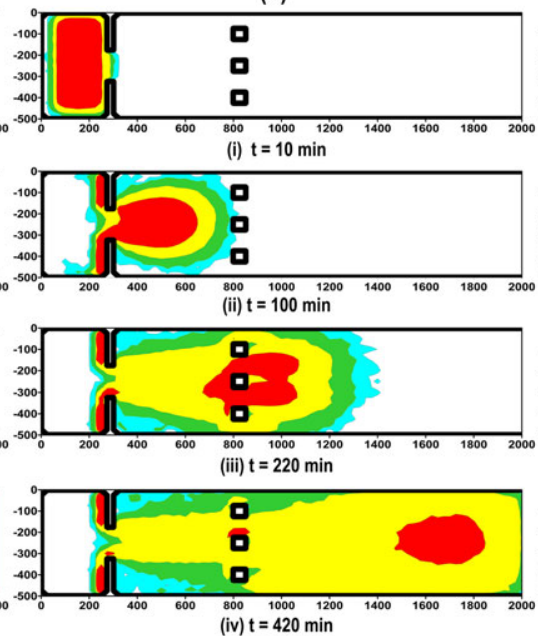

(iv) $\mathrm{t}=420 \mathrm{~min}$
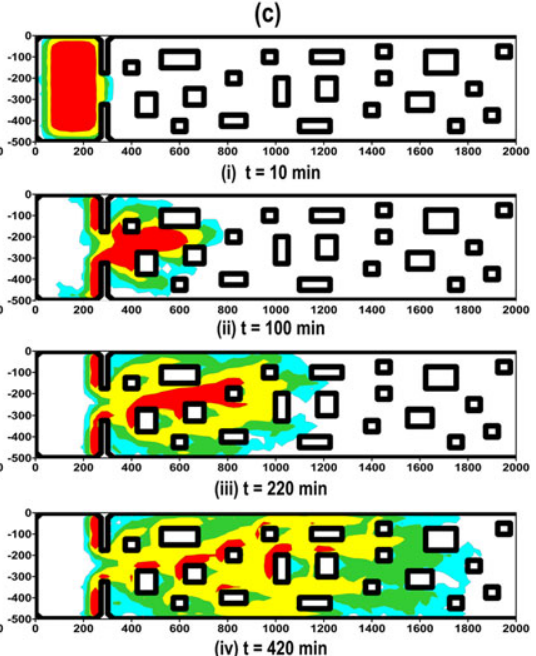

(iv) $\mathrm{t}=420 \mathrm{~min}$

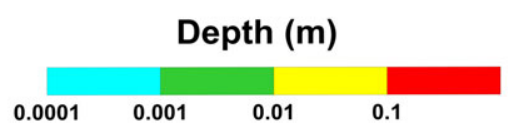

FIGURE 9 Simulation of a pulse with a finite duration of the diffusive wave for time periods of (i) $t=10 \mathrm{~min}$, (ii) $t=100 \mathrm{~min}$, (iii) $t=220 \mathrm{~min}$, and (iv) $t=420 \mathrm{~min}$ in a hypothetical city, consisting of (a) single block of buildings, (b) detached buildings, and (c) random buildings (digital elevation model: uniform global slope)
The general order of depths in all types of building configurations from large values to small values is random buildings, a single T2 block of buildings, and detached buildings (see Table 2). In some scenarios, depths are larger for the domain of single block of buildings than the domain of random buildings (e.g., at $t=420 \mathrm{~min}$ and $t=840 \mathrm{~min}$ ) due to the fact that the flood inundation depths for the former type of domain are accumulated just in front of the single block of buildings, which has a large frontal area. Maximum depths in Table 2 reflect the existence of many random buildings and a large frontal area in the case of a single block of buildings, which offers more resistance to the flow as compared with three detached buildings.

\section{2 | Case 2: A pulse of flood with an infinite} duration

An infinite duration pulse (see Figure $3 \mathrm{~b}$ ) implies that the flood keeps coming from the reservoir at dam breach towards the downstream 
(a)

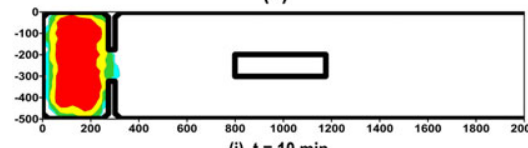

(i) $\mathrm{t}=10 \mathrm{~min}$
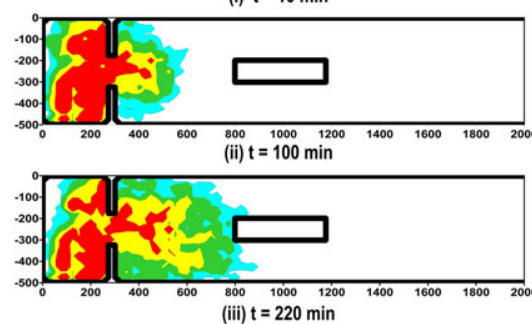

(iii) $\mathrm{t}=220 \mathrm{~min}$

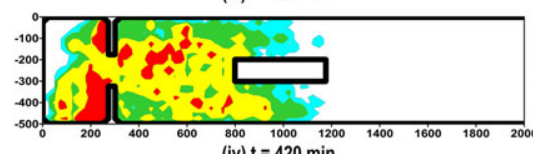

(iv) $\mathrm{t}=420 \mathrm{~min}$ (b)

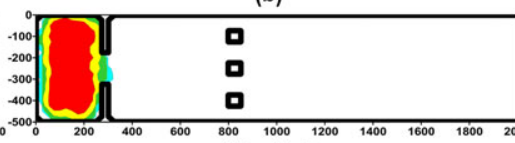

(i) $\mathrm{t}=10 \mathrm{~min}$
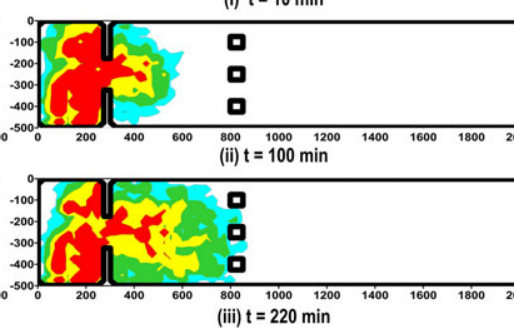

(iii) $\mathrm{t}=\mathbf{2 2 0} \mathrm{min}$

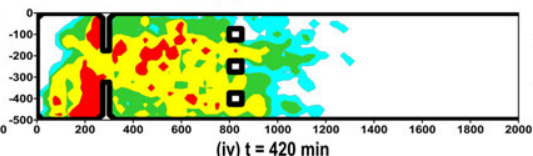

(iv) $\mathrm{t}=420 \mathrm{~min}$

Depth $(m)$

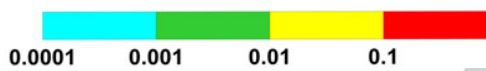

FIGURE 10 Simulation of a pulse with a finite duration of the diffusive wave for time periods of (i) $t=10 \mathrm{~min}$, (ii) $t=100 \mathrm{~min}$, (iii) $t=220 \mathrm{~min}$, and (iv) $t=420 \mathrm{~min}$ in a hypothetical city, consisting of (a) single block of buildings, (b) detached buildings, and (c) random buildings (digital elevation model: randomly variable local slopes)

TABLE 2 Summary of results, representing maximum depths for three cases under various scenarios

$t=10 \min t=20 \min t=100 \min t=220 \min t=420 \min t=840 \mathrm{~min}$

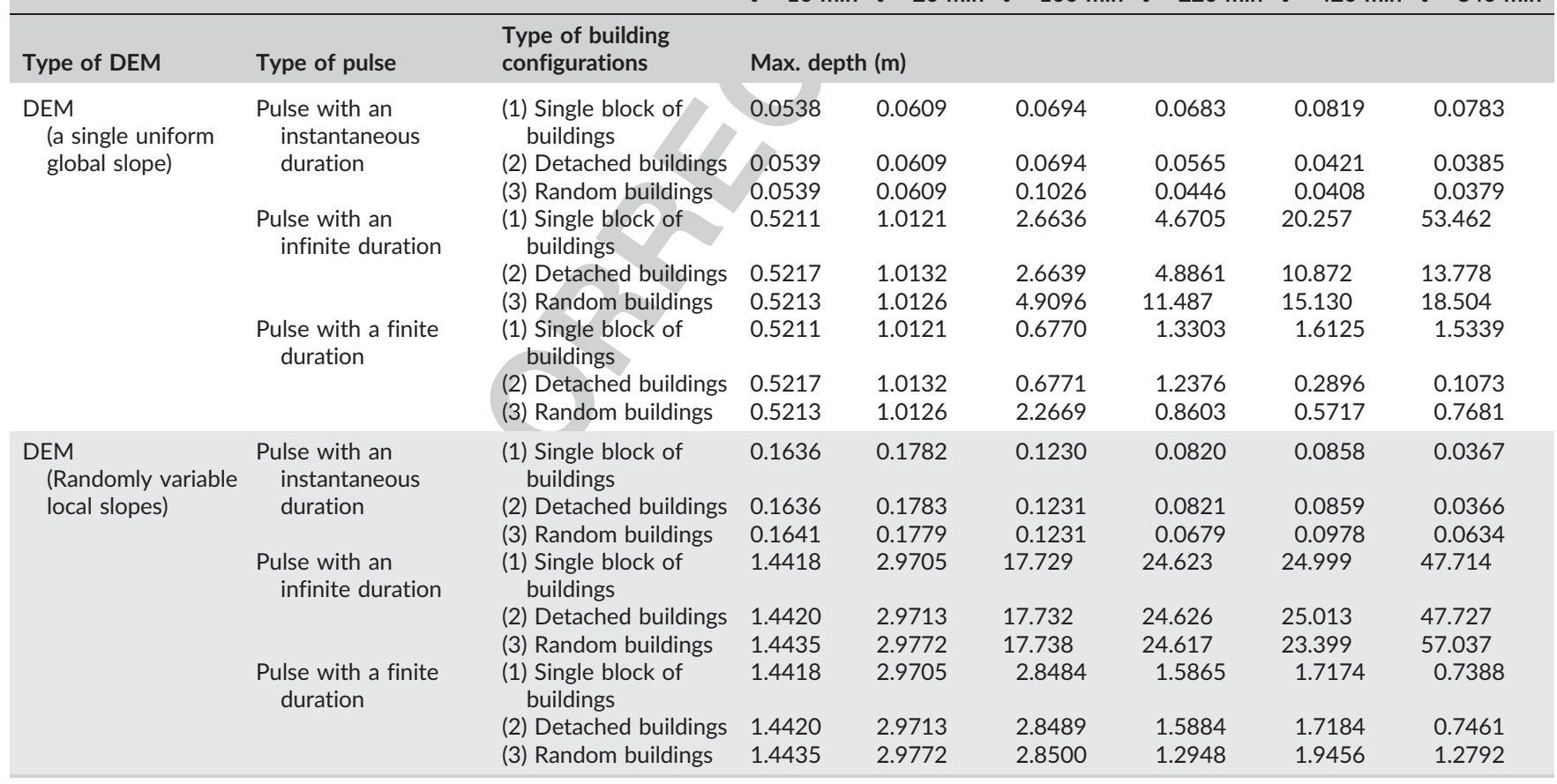

Note. DEM: digital elevation model. hypothetical city for an unlimited duration after the breach of the dam. This condition is not practically possible because a flood has to stop after a certain duration. However, this case is presented as the other extreme case that is opposite to the Case 1. Figures 7 and 8 illustrate six types of simulations for Case 2.

The maximum depth is represented by a red colour contour which is initially visible in the reservoir. As time passes, the value of the depth away from the reservoir starts to and keeps rising due to the accumulation of pulses at every time step for an infinite duration. When the flood flow faces the buildings, it starts moving around them by the diffusion process. In the case of a DEM with a uniform global slope (Figure 7), RWPT simulation results show that the DW keeps propagating and surrounds the buildings at $t=220 \mathrm{~min}$ for the single block of buildings and detached buildings and at $t=100 \mathrm{~min}$ for the random buildings. 
After surrounding the buildings, the particles change their tracks and start moving around buildings. Buildings offer barriers to the propagation of the particles. Particles accumulate in front of the buildings, thereby causing inundation depths to increase, which is the expected behaviour in the real world situations. In the case of a DEM with randomly variable local slopes (Figure 8), the diffusion of the wave starts slowly in contrast to the former case where the diffusion is rapid. The pattern of diffusion is also different, and the locations of maximum depths are random. Simulated results show that maximum depths do not occur continuously. This means that pulses accumulate continuously due to the continuous feeding of the flood from the dam. The difference in the pattern of the DW is due to the random changes in local slopes of the DEM.

\subsection{Case 3: A pulse of flood with a finite duration}

A finite duration of the pulse (see Figure 3c) represents a typical flood in nature. For this case, the flood starts to propagate from the location of the dam breach for a certain duration, where it is treated as a continuous pulse. When the pulse stops propagating from the reservoir after the duration $\tau$, the flood volume that has entered the hypothetical city is propagated in the downstream direction.

At $t=10 \mathrm{~min}$, contours of depths are initially distributed over a small area and at $t=20 \mathrm{~min}$, again starting from the same location, the DW is propagated a little further covering more areas. This happens because the DW has a duration of $20 \mathrm{~min}$, and new depths must be added to previous depths (convolution), and the pulse is propagating from the reservoir location. Here, the DW has the same propagation pattern as it has in the case of an infinite duration of a pulse. But once the feeding of the DW is stopped after $20 \mathrm{~min}$, the algorithm is programmed to deconvolute the depths after $20 \mathrm{~min}$. This case is represented in Figures 9 and 10.

In the case of a DEM with a uniform global slope, the DW starts to propagate around the single block of buildings and detached buildings at $t=220 \mathrm{~min}$. The domain of random buildings is the most realistic representation of a city. Until $t=20 \mathrm{~min}$, depths continuously increase due to the flood flow from the reservoir location. After $20 \mathrm{~min}$, no more volume is added, and the flood starts moving in the direction of flow through the streets and around the buildings. The maximum depths occur around the buildings for some time because buildings block movement of the particles. The propagation of the DW does not reach the right boundary of the domain by $t=420 \mathrm{~min}$, in contrast to the other two types of domains because of the presence of numerous randomly distributed buildings decelerating the wave propagation. The DW propagates slowly in the case of a DEM with randomly variable local slopes because undulated surfaces slow down the speed of the wave build-up.

Table 2 summarizes flood inundation depths resulting from simulations for the propagation of the DW in a hypothetical city. Two different types of DEM are used in order to encompass all types of surface elevations. Simulated results show the robustness of the proposed model, thereby, it can be used for all types of DEMs ranging from the uniform slope to the randomly distributed slopes.

In Figure 11, subfigures a-c, subfigures $d-f$, and subfigures g-i F11 represent depth hydrographs for three chosen locations in the hypothetical city (viz., Locations 1, 2, and 3) computed for the single block where the DEM with a uniform global slope is represented by $S_{1}$ and the DEM with randomly variable local slopes but with a uniform global slope is represented by $S_{2}$ 
of buildings, detached buildings, and random buildings, respectively. In the same Figure 11, subfigures a, d, and g, subfigures b, e, and h, and subfigures $\mathrm{c}, \mathrm{f}$, and i represent depth hydrographs of a pulse with an instantaneous duration, an infinite duration, and a finite duration, respectively.

For a DEM with a uniform global slope, the plots of the depth hydrographs for an instantaneous duration pulse and a finite duration pulse end after a finite duration, but the difference between the two lies in the depth magnitudes. In contrast, the depth hydrograph for an infinite duration is continuous. For a DEM with randomly variable slopes, the overall shape of the depth hydrographs for an instantaneous duration pulse, an infinite duration pulse, and a finite duration pulse is similar to the ones discussed for the case of a DEM with a uniform global slope. The difference between the depth hydrographs for the two different types of DEMs lies in the local shapes and the maximum values of the depths.

\section{4 | DISCUSSION}

No numerical solution schemes exist that are exact and completely error-free. Although the RWPT simulation method has some shortcomings, it has significant advantages over traditional deterministic schemes. Traditional solutions of the 2-D Saint-Venant equations need massive computations in a short time in order to simulate flow problems such as the dam break problem, flood waves, and so forth The main issues in the traditional techniques are (a) the computational time to solve the continuity equation and the two momentum equations simultaneously and (b) the instability or the numerical diffusion of the numerical schemes due to the chosen time step. A detailed discussion regarding numerical schemes for free surface flows is available in Abbott and Basco (1989). The RWPT method solves the approximate version of the full Saint-Venant equations, which is called the DW model. It is simpler yet mathematically sound in the sense that it is one equation that combines the continuity and the two momentum equations. Due to its explicit nature, it does not suffer from numerical diffusion and is therefore numerically stable. It only suffers from noises on the edges of the water zones which can be avoided by having a sufficient number of particles. In order to avoid overshoot, the time step should be chosen small enough to avoid such a problem (Kinzelbach \& Uffink, 1991).

The RWPT method in the current study is different from the smoothed particle hydrodynamics (SPH) method, which was introduced by Gingold and Monaghan (1977). In the SPH method, the variable under study is represented by particles, where each particle has a spatial distance known as the, "smoothing length." The variable under study is smoothed by a kernel function over the smoothing length. The physical quantity of any particle can be obtained by summing the relevant properties of all the particles which lie within the range of the kernel. However, the RWPT method is a stochastic process that is used to simulate Lévy flight and diffusion models such as a Brownian motion. Similar to the SPH method, the variable under study is represented by particles, but these particles have neither kernel function nor size (smoothing length). Particles have to move according to some rules and change their position in time.
One of the main limitations of the RWPT method is the random fluctuations of computed volumes from the number of particles. According to Kinzelbach (1988), these random fluctuations have an inverse relationship with the square root of the particle count. Therefore, increasing the number of particles can improve the accuracy of the results obtained. This section presents a detail statistical analysis of this limitation.

A sensitivity analysis was performed for selecting the appropriate number of particles to represent the given volume of a hydrograph, where 1,000, 2,500, 5,000, 7,500, 10,000, 25,000, 50,000, and 100,000 particles were chosen for the analysis. Flow hydrographs were computed for comparison at three locations, as shown in Figure 2 (represented by the purple colour stars). These locations are the following: Location $1(350 \mathrm{~m},-250 \mathrm{~m})$, Location $2(900 \mathrm{~m}$, $-250 \mathrm{~m})$, and Location $3(1,500 \mathrm{~m},-250 \mathrm{~m})$.

Figure 12 shows that the overall shape of the hydrograph is not $\mathbf{F 1 2}$ affected by the number of particles. However, the statistical investigation shows that pronounced numerical fluctuations occur with a lesser
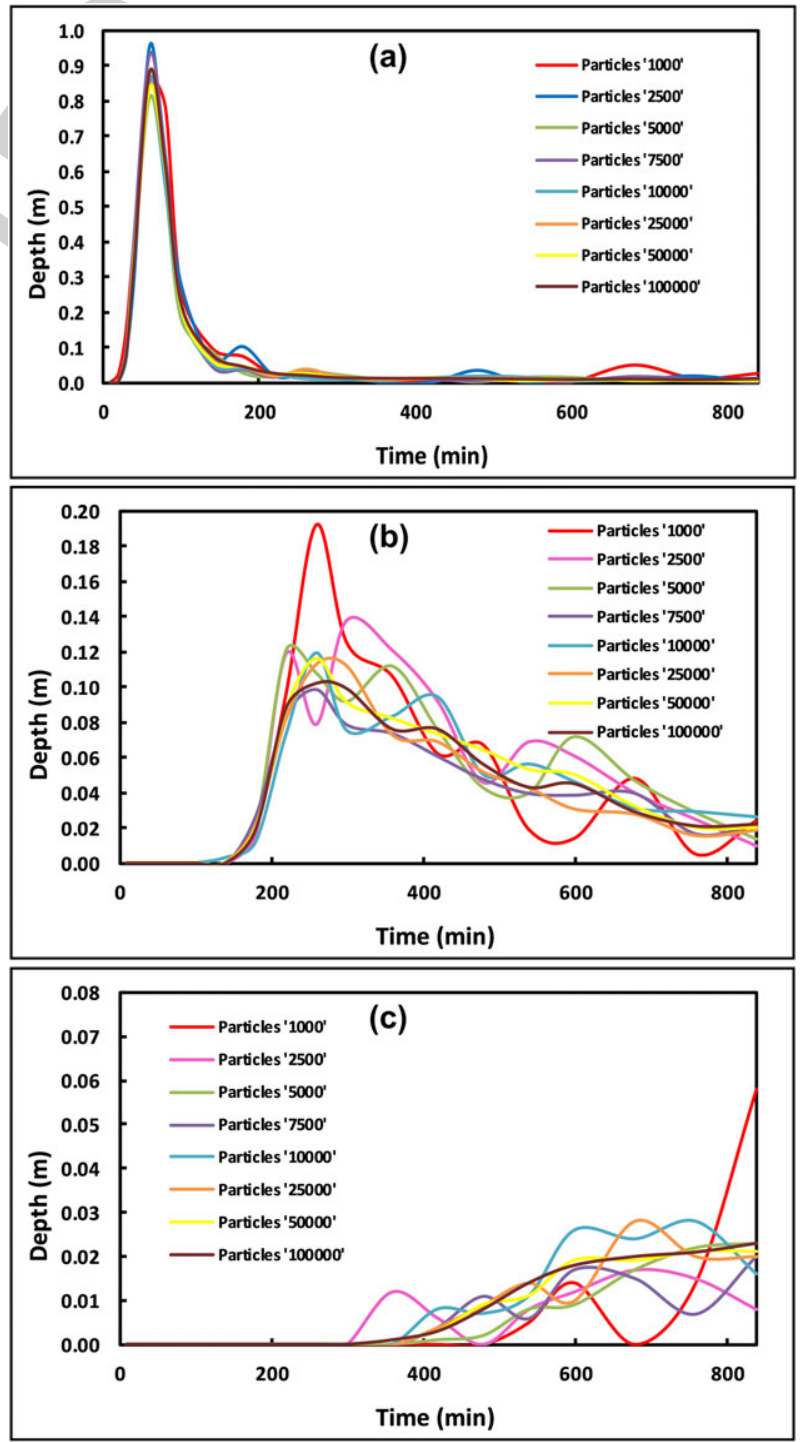

FIGURE 12 Sensitivity analysis for the number of particles for simulation of a diffusive wave 
TABLE 3 Representation of RMSE values of a different number of particles for three chosen locations (Locations 1, 2, and 3) in the hypothetical city

\begin{tabular}{|c|c|c|c|c|c|c|c|c|}
\hline & \multicolumn{8}{|c|}{ Number of particles } \\
\hline & 1,000 & 2,500 & 5,000 & 7,500 & 10,000 & 25,000 & 50,000 & 100,000 \\
\hline & \multicolumn{8}{|c|}{ RMSE (m) } \\
\hline Location 2 & 0.025 & 0.018 & 0.014 & 0.007 & 0.010 & 0.006 & 0.005 & 0.000 \\
\hline Location 3 & 0.010 & 0.005 & 0.003 & 0.004 & 0.003 & 0.003 & 0.001 & 0.000 \\
\hline
\end{tabular}

Note. RMSE: root mean square error.

number of particles, meaning the effect can be diminished by increasing the particle number. Root mean square error (RMSE) analysis was performed for the different numbers of particles tested. The case for 100,000 particles served as a reference case for the RMSE compariT3 sons. In Table 3, the general trend of the RMSE values for the different numbers of particles indicates that the error decreases as the number of particles increases. The RMSE values converge from $0.046 \mathrm{~m}$ at 1,000 particles to $0.013 \mathrm{~m}$ at 50,000 particles, $0.025 \mathrm{~m}$ at 1,000 particles to $0.005 \mathrm{~m}$ at 50,000 particles, and $0.01 \mathrm{~m}$ at 1,000 particles to $0.001 \mathrm{~m}$ at 50,000 particles for Locations 1,2 , and 3 , respectively. Thereby, statistical results indicate that selecting numerous particles will smooth out the fluctuations in the flow hydrographs (as demonstrated in Figure 12) and will produce plausible results.

The paper presents a stochastic RWPT technique to solve the DW equation in 2-D. Elfeki et al. (2011) solved Equation (20) by using the RWPT model in which they represented the volume of a hydrograph with particles moving in the given flow field. This paper presents an improved algorithm for computing the inundation depths from the propagation of a DW in a city. In this method, the volume of the hydrograph is represented by a pulse with a certain duration. The model is based on the particle tracking technique, thus, the volume of hydrograph is represented by a finite number of particles in which each particle carries a fixed amount of volume of the hydrograph. The volume per particle is obtained by dividing the volume of the pulse by the number of particles. The superposition of the convective movement and the diffusive movement of these particles in the flow field provide an analogy with the propagation of the DW in the same flow field. The dispersion process allows the spreading of particles laterally in front of the buildings. This is based on the tracking algorithm which is aligned with the flow velocity directions.

The algorithm presented by Elfeki et al. (2011) has several shortcomings. Their algorithm is based only on a continuous pulse (an infinite duration pulse). This paper presents three different cases in terms of the duration of the DW. Quantitative comparisons of results for these cases (see Table 2) show that simulations for an instantaneous duration and an infinite duration produce underestimated and overestimated inundation depths, respectively, and the case of a finite duration pulse produces reasonable results for flood inundation depths. The finite duration case is the correct boundary condition for the flood simulations. However, the comparison is essential to establish a fact that Elfeki et al. (2011) used a wrong boundary condition for the RWPT based simulation. Therefore, this study presents an improved RWPT algorithm with the emphasis on using correct boundary conditions.

\section{5 | CONCLUSIONS}

This paper proposes an alternate way for modelling flash floods. The DW is modelled stochastically as an equation solved by the explicit random walk method. The proposed stochastic method has two major advantages over the traditional deterministic numerical schemes:

1. Lesser computational costs, and

2. No instability issues because of its efficiency.

A comparison is drawn among three cases in this study: (a) a pulse with an instantaneous duration, (b) a pulse with an infinite duration, and (c) a pulse with a finite duration. The three cases are simulated in three different domains of building configurations: (a) single block of buildings, (b) detached buildings, and (c) random buildings with two different types of gradients: (a) a uniform global gradient and (b) varying local gradients.

1. The three cases show the different patterns of the propagation of DWs.

2. The DW propagates in the streets around the buildings, irrespective of the number of buildings present.

3. The DW moves rapidly as long as it does not face any building or a block of buildings.

4. Greater depths occur in front of the buildings and smaller depths occur away from the buildings.

5. For an instantaneous duration of the pulse, the depths are very small because of the short duration of the flood wave at the location of the dam breach.

6. For an infinite duration of the pulse, the depths are convoluted over the time steps, and the propagation of the DW at any time period always commences from the same reservoir location.

7. The case of the pulse with a finite duration is the most practical representation of the DW propagation. The flood starts to propagate from the same reservoir location for a certain duration by the principle of the convolution over the time steps. After a certain duration, the feeding of the pulse ends and the DW is simulated in the city on the basis of the available flood flow by the principle of the deconvolution over the time steps. The simulation of the DW in this manner was found to be the most reasonable representation of the flood. 


\section{ACKNOWLEDGEMENT}

We extend our gratitude to the editor and the reviewers for their valuable comments.

\section{CONFLICT OF INTEREST}

We declare that there is no conflict of interest and this research did not receive any specific grant from funding agencies in the public, commercial, or not-for-profit sectors.

\section{ORCID}

Kashif Noor (D) http://orcid.org/0000-0002-3247-1670

\section{REFERENCES}

Abbott, M. B., Basco, D. R. (1989). Computational fluid dynamics-An introduction for engineers. NASA STI/Recon Technical Report A, 90.

Abulaban, A., Nieber, J., \& Misra, D. (1998). Modeling plume behavior for nonlinearly sorbing solutes in saturated homogeneous porous media. Advances in Water Resources, 21, 487-498.

Ali, M. A., Kimura, I., \& Shimizu, Y. (2016). Flood modelling using sub-grid based finite volume approach \& constrained interpolation profile method. In River flow 2016 (pp. 1891-1895). CRC Press.

Banton, O., Delay, F., \& Porel, G. (1997). A new time domain random walk method for solute transport in 1-D heterogeneous media. Groundwater, 35, 1008-1013.

Bates, P. D., Horritt, M. S., \& Fewtrell, T. J. (2010). A simple inertial formulation of the shallow water equations for efficient two-dimensional flood inundation modelling. Journal of Hydrology, 387, 33-45.

Bear, J. (2013). Dynamics of fluids in porous media. Courier Corporation.

Bradford, S. F., \& Sanders, B. F. (2002). Finite-volume model for shallowwater flooding of arbitrary topography. Journal of Hydraulic Engineering $128,289-298$

Chow, V. T. (1959). Open channel hydraulics. McGraw-Hill.

Cobby, D. M., Mason, D. C., Horritt, M. S., \& Bates, P. D. (2003). Twodimensional hydraulic flood modelling using a finite-element mesh decomposed according to vegetation and topographic features derived from airborne scanning laser altimetry. Hydrological Processes, 17, $1979-2000$

Elfeki, A., Ewea, H., Al-Amri, N. (2011). Simulation of urban flooding by diffusive wave model: Jeddah flood 2009 case study. In: First International Geomatics Symposium in Saudi Arabia. King Abdel Aziz Univ, Jeddah Google Scholar

Emmanuel, S., \& Berkowitz, B. (2007). Continuous time random walks and heat transfer in porous media. Transport in Porous Media, 67, 413-430.

Fennema, R. J., \& Chaudhry, M. H. (1987). Simulation of one-dimensional dam-break flows. Journal of Hydraulic Research, 25, 41-51. https:// doi.org/10.1080/00221688709499287

Ferrick, M. G., Bilmes, J., \& Long, S. E. (1984). Modeling rapidly varied flow in tailwaters. Water Resources Research, 20, 271-289. https://doi.org/ 10.1029/WR020i002p00271

Gingold, R. A., \& Monaghan, J. J. (1977). Smoothed particle hydrodynamics: Theory and application to non-spherical stars. Monthly Notices of the Royal Astronomical Society, 181, 375-389.

Gjetvaj, G. (1997). Boundary conditions in random walk simulations of groundwater contaminant transport. WIT Transactions on Ecology and the Environment, 20.

Haltas, I., Tayfur, G., \& Elci, S. (2016). Two-dimensional numerical modeling of flood wave propagation in an urban area due to Ürkmez dam-break, İzmir, Turkey. Natural Hazards, 81, 2103-2119.

Horritt, M., \& Bates, P. (2002). Evaluation of 1D and 2D numerical models for predicting river flood inundation. Journal of Hydrology, $268,87-99$
Kazezyılmaz-Alhan, C. M., \& Medina, M. A. Jr. (2007). Kinematic and diffusion waves: Analytical and numerical solutions to overland and channel flow. Journal of Hydraulic Engineering, 133, 217-228. https://doi.org/ 10.1061/(ASCE)0733-9429(2007)133:2(217)

Kinzelbach, W. (1986). Groundwater modelling: An introduction with sample programs in BASIC. Elsevier.

Kinzelbach, W. (1988). The random walk method in pollutant transport simulation. In Groundwater flow and quality modelling (pp. 227-245). Springer.

Kinzelbach, W., \& Uffink, G. (1991). The random walk method and extensions in groundwater modelling. In Transport processes in porous media (pp. 761-787). Springer.

Lax, P., \& Wendroff, B. (1960). Systems of conservation laws. Communications on Pure and Applied Mathematics, 13, 217-237. https://doi.org/ 10.1002/cpa.3160130205

Leandro, J., Chen, A. S., \& Schumann, A. (2014). A 2D parallel diffusive wave model for floodplain inundation with variable time step (P-DWave). Journal of Hydrology, 517, 250-259. https://doi.org/10.1016/j.jhydrol. 2014.05.020

Liang, Q., Chen, K.-c., Jingming, H., Xiong, Y., Gang, W., \& Qiang, J. (2016). Hydrodynamic modelling of flow impact on structures under extreme flow conditions. Journal of Hydrodynamics, Series B, 28, 267-274.

Liu, Y. B., Gebremeskel, S., De Smedt, F., Hoffmann, L., \& Pfister, L. (2003). A diffusive transport approach for flow routing in GIS-based flood modeling. Journal of Hydrology, 283, 91-106. https://doi.org/ 10.1016/S0022-1694(03)00242-7

McCuen, R. H. (1989). Hydrologic analysis and design. Englewood Cliffs, NJ: Prentice-Hall.

Moramarco, T., Pandolfo, C., \& Singh, V. P. (2008). Accuracy of kinematic wave and diffusion wave approximations for flood routing. I: Steady analysis. Journal of Hydrologic Engineering, 13, 1078-1088. https:// doi.org/10.1061/(ASCE)1084-0699(2008)13:11(1078)

Moussa, R. (1996). Analytical Hayami solution for the diffusive wave flood routing problem with lateral inflow. Hydrological Processes, 10, 1209-1227.

Moussa, R., \& Bocquillon, C. (2009). On the use of the diffusive wave for modelling extreme flood events with overbank flow in the floodplain. Journal of Hydrology, 374, 116-135. https://doi.org/10.1016/j. jhydrol.2009.06.006

Noor, K., \& Elfeki, A. M. M. (2017). Development of a generalized Hayami solution for modelling of a diffusive flood wave in arid and non-arid regions. Natural Hazards, 88, 121-144. https://doi.org/10.1007/ s11069-017-2859-6

O'brien, J., Julien, P., \& Fullerton, W. (1993). Two-dimensional water flood and mudflow simulation. Journal of Hydraulic Engineering, 119, 244-261.

Ponce, V. M. (1990). Generalized diffusion wave equation with inertial effects. Water Resources Research, 26, 1099-1101. https://doi.org/ 10.1029/WR026i005p01099

Ponce, V. M., \& Simons, D. B. (1977). Shallow wave propagation in open channel flow. Journal of the Hydraulics Division, 103, 1461-1476.

Prestininzi, P. (2008). Suitability of the diffusive model for dam break simulation: Application to a CADAM experiment. Journal of Hydrology, 361, 172-185.

Salamon, P., Fernàndez-Garcia, D., \& Gómez-Hernández, J. J. (2006). A review and numerical assessment of the random walk particle tracking method. Journal of Contaminant Hydrology, 87, 277-305.

Schubert, J. E., Sanders, B. F., Smith, M. J., \& Wright, N. G. (2008). Unstructured mesh generation and landcover-based resistance for hydrodynamic modeling of urban flooding. Advances in Water Resources, 31, 1603-1621.

Tompson, A. F. (1993). Numerical simulation of chemical migration in physically and chemically heterogeneous porous media. Water Resources Research, 29, 3709-3726. 
Tsai, C. W. (2003). Applicability of kinematic, noninertia, and quasi-steady dynamic wave models to unsteady flow routing. Journal of Hydraulic Engineering, 129, 613-627. https://doi.org/10.1061/(ASCE)07339429(2003)129:8(613)

Uffink, G. (1986). A random-walk simulation of dispersion at an interface between fresh and saline groundwater. In: Proceedings of the 9th Salt Water Intrusion Meeting.

Uffink, G. J. M. (1990). Analysis of dispersion by the random walk method.

Yu, D., \& Lane, S. N. (2006). Urban fluvial flood modelling using a twodimensional diffusion-wave treatment, part 1: Mesh resolution effects. Hydrological Processes, 20, 1541-1565.
Zhang, T., Feng, P., Maksimović, Č., \& Bates, P. D. (2016). Application of a three-dimensional unstructured-mesh finite-element flooding model and comparison with two-dimensional approaches. Water Resources Management, 30, 823-841.

How to cite this article: Noor K, Elfeki AMM. Stochastic modelling of a diffusive wave for flood propagation using the random walk particle tracking method in a hypothetical city. Hydrological Processes. 2018;1-15. https://doi.org/10.1002/ hyp.13168 